\title{
A COLLAPSE SURFACE FOR PERFORATED PLATES WITH TRIANGULAR PATTERNS FOR LIGAMENT EFFICIENCIES BETWEEN 0.05 AND 0.50
}

\author{
D.P. Jones \\ J.L. Gordon
}

\section{NOTICE}

This report was prepared as an account of work sponsored by an agency of the United States Government. Neither the United States Government nor any agency thereof, nor any of their employees, nor any of their contractors, subcontractors or their employees, makes any warranty, express or implied, or assumes any legal liability or responsibility for the accuracy, completeness, or any third party's use or the results of such use of any information, apparatus, product, or process disclosed, or represents that its use would not infringe privately owned rights. Reference herein to any specific commercial product, process, or service by trade name, trademark, manufacturer, or otherwise, does not necessarily constitute or imply its endorsement, recommendation, or favoring by the United States Government or any agency thereof or its contractors or subcontractors. The views and opinions of authors expressed herein do not necessarily state or reflect those of the United States Government or any agency thereof. 
B-T-3300

Page 2

(This Page Intentionally Blank) 


\title{
Collapse Surfaces for Perforated Plates with Triangular Penetration Patterns for. Ligament Efficiencies Between 0.05 and 0.50
}

\author{
D.P. Jones and J. L. Gordon \\ Bechtel Bettis, Inc \\ West Mifflin, PA 15122-0079
}

\begin{abstract}
Collapse surfaces are developed for thick perforated plates containing a triangular penetration pattern with ligament efficiencies of $0.05,0.10,0.15,0.2,0.3$, and 0.5 using elasticperfectly plastic FEA analysis. The FEA data was fit to a fourth-order collapse function which is appropriate for the development of an equivalent solid elastic-perfectly plastic plasticity model for perforated plates with triangular penetration patterns. This type of model can be conveniently used to develop a limit load capability for perforated plate analysis. It was shown that the fourth-order function is reasonable for ligament efficiencies between 0.15 to 0.5 . Comparing the fourthorder collapse function to FEA data suggests that an alternate collapse function is needed for ligament efficiencies less than 0.15. A linear interpolation method was shown to be appropriate for ligament efficiencies between 0.15 and 0.5 .
\end{abstract}

\section{INTRODUCTION}

This paper extends the elastic-perfectly plastic equivalent solid plate (EPP-EQS) analysis method for the calculation of limit loads of flat perforated plates to a wide range of ligament efficiencies. The EPP-EQS model is based on the fourth-order yield function, proposed by
Reinhardt [1, 2]. Gordon et. al. [3] and Jones et. al. [4] used the fourth-order function to develop a full elastic-plastic flow model appropriate for implementation into commercially available EPP-FEA programs. The resulting elastic-perfectly plastic flow model provides an equivalent solid elasticperfectly plastic (EQS-EPP) plasticity formulation that is useful in calculating limit loads for thick perforated plates with triangular penetration patterns.

Gordon et. al. [3] developed a fourth-order collapse surface based on the assumption that the penetration pattern is in a state of generalized plane strain applicable to a single ligament efficiency. This paper examines the range over which the fourth-order collapse function applies and provides coefficients for the collapse function within that range. Using generalized plane strain assumptions, EPP-FEA models were used to develop collapse surfaces for ligament efficiencies of $0.05,0.10,0.15,0.20,0.30$, and 0.50 . These surfaces were used to assess the range of ligament efficiencies over which it is appropriate to use a fourth-order collapse function. 


\section{NOMENCLATURE}

\begin{tabular}{|c|c|}
\hline ? & $\begin{array}{l}\text { Distance between penetration } \\
\text { centers, } \mathrm{mm}\end{array}$ \\
\hline h & Minimum ligament width, $\mathrm{mm}$ \\
\hline$\mu=h P$ & Ligament efficiency \\
\hline$\sigma_{i}, \varepsilon_{i}$ & $\begin{array}{l}\text { Stress and strain components for } i= \\
x x, y y, z z, x y, M P a \text { and } \mathrm{mm} / \mathrm{mm}\end{array}$ \\
\hline$\sigma_{*}$ & $\begin{array}{l}\text { Tangential stress component at } \\
\text { penetration surface, } \mathrm{MPa}\end{array}$ \\
\hline$\mu S_{y}$ & $\begin{array}{l}\text { Effective yield stress of EQS } \\
\text { material, } \mathrm{MPa}\end{array}$ \\
\hline & Yield stress, MPa \\
\hline & $\begin{array}{l}\text { Coefficients for fourth-order } \\
\text { collapse function }\end{array}$ \\
\hline$Z_{1}, Z_{2}$ & $\begin{array}{l}\text { Out-of-plane constants for collapse } \\
\text { function }\end{array}$ \\
\hline$E, v$ & $\begin{array}{l}\text { Young's modulus and Poisson's } \\
\text { ratio of base metal }\end{array}$ \\
\hline$E^{\star} / E, v^{*}$ & $\begin{array}{l}\text { Equivalent solid effective elastic } \\
\text { constants }\end{array}$ \\
\hline 25 & Equivalent solid \\
\hline
\end{tabular}

\section{PROBLEM STATEMENT}

Consider an infinite array of penetrations arranged in an equilateral pattern as shown in Figure 1. If the penetrations are very small compared to all other dimensions of the structure, symmetry of the deformation of an infinite array of such penetrations allows the identification of a unit cell that can be used to analyze the response of the pattern to general far field loading. The unit cell is shown in Figure 2. Limit load solutions are sought for the unit cell for various ratios of loading along the $x$ and $y$ axes. By determining the loads for which any additional increment of load causes plastic collapse of the unit cell, a collapse surface is obtained which is appropriate for assessing the load interaction effects on the limit load of a perforated plate.
Figure 1. Triangular penetration pattern.

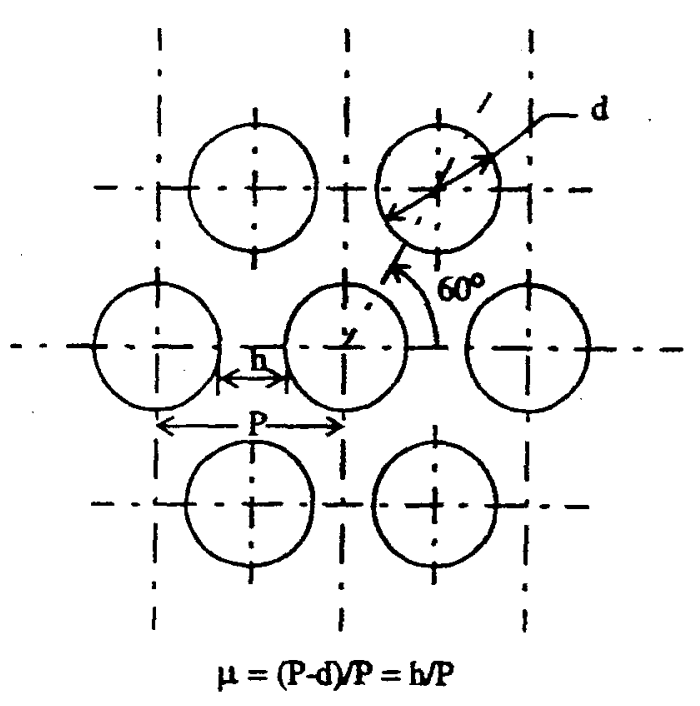

Reinhardt [1, 2] demonstrated that a fourthorder collapse function is the lowest order collapse function that describes the behaviour required by $60^{\circ}$ symmetry of the equilaterial array. This function is given by the equation

$$
\begin{aligned}
\sigma_{e f f}=\{ & \frac{1}{4}\left\{M\left(\sigma_{x x}+\sigma_{y y}\right)^{4}+Q\left(\sigma_{x x}-\sigma_{y y}\right)^{2}+4 \tau_{x y}^{2}\right]^{2} \\
& +R\left(\sigma_{x x}+\sigma_{y y}\right)^{2}\left[\left(\sigma_{x x}-\sigma_{y y}\right)^{2}+4 \tau_{x y}^{2}\right] \\
& \left.+T\left(\sigma_{x x}^{2}-\sigma_{y y}^{2}\right)\left[\left(\sigma_{x x}-\sigma_{y y}\right)^{2}-12 \tau_{x y}^{2}\right]\right\}^{0.5} \\
+Y\left[\sigma_{=}^{2}\right. & \left.\left.-\sigma_{=}\left(\sigma_{x}+\sigma_{y y}\right)\right]+3 Z_{1} \tau_{y z}^{2}+3 Z_{2} \tau_{x x}^{2}\right\}^{0.5} \\
= & S_{0}
\end{aligned}
$$

Since the out-of-plane (z-direction) is treated in the usual quadratic fashion, only the fourthorder terms relating the in-plane collapse behavior are considered in this paper. Reinhardt [2] showed that it is convenient to use the transform 


$$
\left\{\begin{array}{l}
s_{1} \\
s_{z} \\
s_{3}
\end{array}\right\}=\left\{\begin{array}{c}
\left(\sigma_{x}+\sigma_{y y}\right) / 2 \\
\left(\sigma_{x x}-\sigma_{y y}\right) / 2 \\
\tau_{x y}
\end{array}\right\}
$$

so that the collapse surface in the plane of the penetrations, with all out-of-plane stress $=0$, is

$$
\begin{aligned}
\sigma_{e n}= & \\
& {\left[M s_{1}^{4}+Q\left(s_{2}^{2}+s_{3}^{2}\right)^{2}+R s_{1}^{2}\left(s_{2}^{2}+s_{3}^{2}\right)+\right.} \\
& \left.T s_{1} s_{2}\left(s_{2}^{2}-3 s_{3}^{2}\right)\right]^{0.25}=S_{0}
\end{aligned}
$$

Gordon et. al. [3] and Jones et. al. [4] developed an EPP flow model based on the fourth-order function and presented numerical results for a ligament efficiency of 0.32 . The purpose of this paper is to determine the range of ligament efficiencies for which Equation (3) is reasonable. Collapse surfaces are determined for a broad range of ligament efficiencies and the $M, Q, R$, and $T$ coefficients determined for each ligament efficiency. The appropriateness of the fourth-order function is then assessed by comparing the equation with the actual FEA data.

Figure 2. Unit Cell.

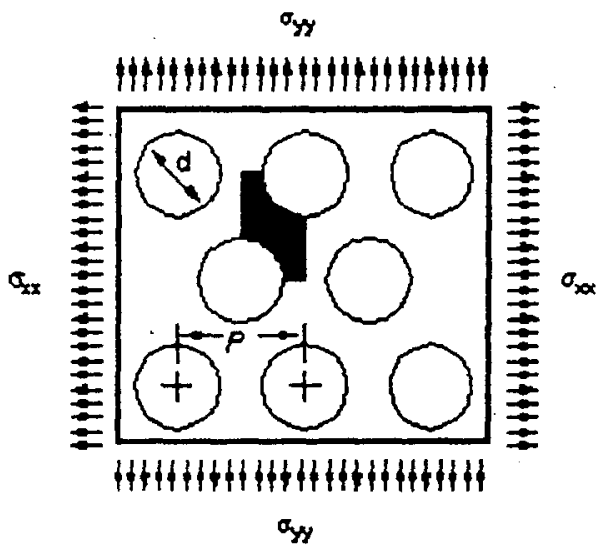

\section{METHOD OF SOLUTION}

The method which was utilized in this work consists of the following steps:

1. Finite element models were developed for unit cells with ligament efficiencies ranging from 0.05 to 0.50 .

2. Limit load solutions were obtained for each of the unit cell models for numerous inplane load combinations.

3. For each of the unit cell models, a best-fit curve was determined for the limit load solutions, producing the coefficients $M, Q$, $R$ and $T$.

4. The $M, Q, R$, and $T$ coefficients are then used to predict the FEA data and the appropriateness of Equation ( 3 ) is assessed by graphical comparison.

5. Evaluate the table look-up method against a known solution for a ligament efficiency of 0.32 .

Step 3 is carried out by first calculating the $Q$ term directly from the $s_{3}$ or $\tau_{x y}$ case where $s_{1}=$ $s_{2}=0.0$. The curve fitting function of the MATHEMATICA [5] program is then used to obtain a best-fit for the $M, R$, and T coefficients so that Equation (3) matches the EPP.FEA data defining the collapse surfaces for an interaction of $s_{1}$ and $s_{2}$ with $s_{3}=0.0$.

\section{MODEL DESCRIPTION}

A basic two-dimensional (2D) generalized plane strain EPP-FEA model is used to obtain the collapse surfaces. The pitch was held constant and set equal to one. The radius of the penetration was varied to obtain the various $h / P$ models. Ligament efficiencies of $0.05,0.10,0.15,0.20,0.30$, and 0.50 were investigated. Young's modulus and Poisson's ratio were chosen to be $26.0 E+6$ psi $(179 E+3$ $\mathrm{MPa}$ ) and 0.3 , respectively. The yield strength 
was taken to be $S_{y}=0.002 E$. Since linear geometry assumptions are used, the limit loads are proportional to yield strength and the actual value chosen is not important.

An elastic-perfectly plastic stress-strain curve was used with ABAQUS [6] to obtain the 2DFEA solutions. The collapse load is defined in these analyses as the load for which a small increase in load produces a very large increase in deflection so that the slope of load-deflection curve approaches zero. Using linear geometry (small-strain, small deformation formulations), this load complies with the theoretical definition of a lower bound limit load.

The FEA mesh is shown in Figure 3. There are

Figure 3. Explicit FEA Model.

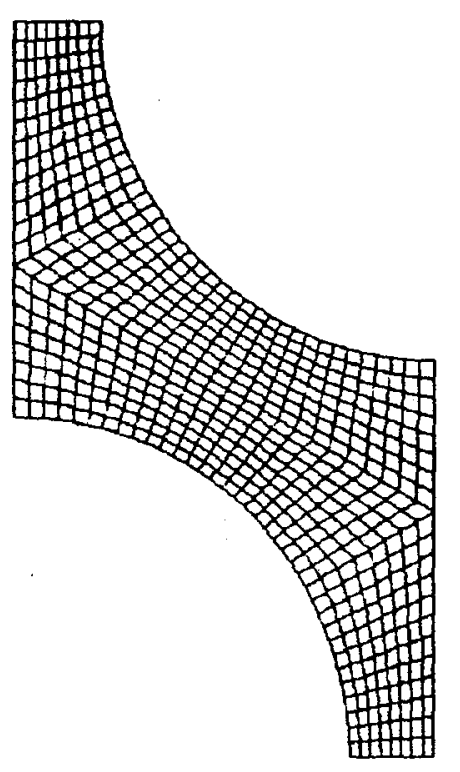

a total of 576 bi-quadratic reduced integration elements and 1857 nodes in each of the models. The boundary conditions for the normal loads or $\left(\sigma_{x x}, \sigma_{y y}\right)$ cases are shown in Figure 4. Surfaces $A-B$ and $E-F$ have symmetry boundary conditions - i.e., the displacements normal to these surfaces are zero and the forces tangential to them are zero. Surface D-E has the displacement components in the $x$ direction constrained so that they are all equal - i.e. the face can only translate uniformly in the $x$ direction. Similarly, surface $B-C$ is constrained such that it can only translate uniformly in the $y$ direction. The model is loaded by specifying the total forces, $F_{x}$ and $F_{y}$, on faces D-E and B-C respectively. The equivalent solid stresses acting on the unit cell are

$\sigma_{x x}=2 F_{x} /(\sqrt{3} P)$

$\sigma_{y y}=2 F_{y} / P$

By varying $F_{x}$ and $F_{y}$, a sufficient number of load cases is run to develop a full surface in quadrants one and four of the collapse surface. Results in quadrants two and three are obtained by reflection.

The boundary conditions for the shear case are shown in Figure 5. The surfaces $B-C$ and $E-F$ were constrained to displace $\delta_{x}$ uniformly in the tangential direction while surfaces D-E and $A-B$ displace $\delta_{y}$ uniformly in the tangential direction - as shown in Figure 5. Tangential displacements were defined on surfaces $A-B$ and $E-F$ while total tangential forces were defined on surfaces $B-C$ and D-E. This case allows for the direct solution of the $Q$ term by the equation

$Q=\left[\mu S_{\gamma} / s_{3}\right]^{1 / 4}$

where $s_{3}$ is the equivalent solid shear stress that causes the unit cell to collapse due to the shear loading (Figure 5). If $F_{x y}$ is the load on surface D-E that causes the unit cell to collapse, then $s_{3}$ in Equation (5) is

$s_{3}=2 F_{x y}(\sqrt{3} P)$ 
B-T-3300

Page 7

Figure 4. Boundary Conditions for $F_{x}$ and $F_{y}$ Case.

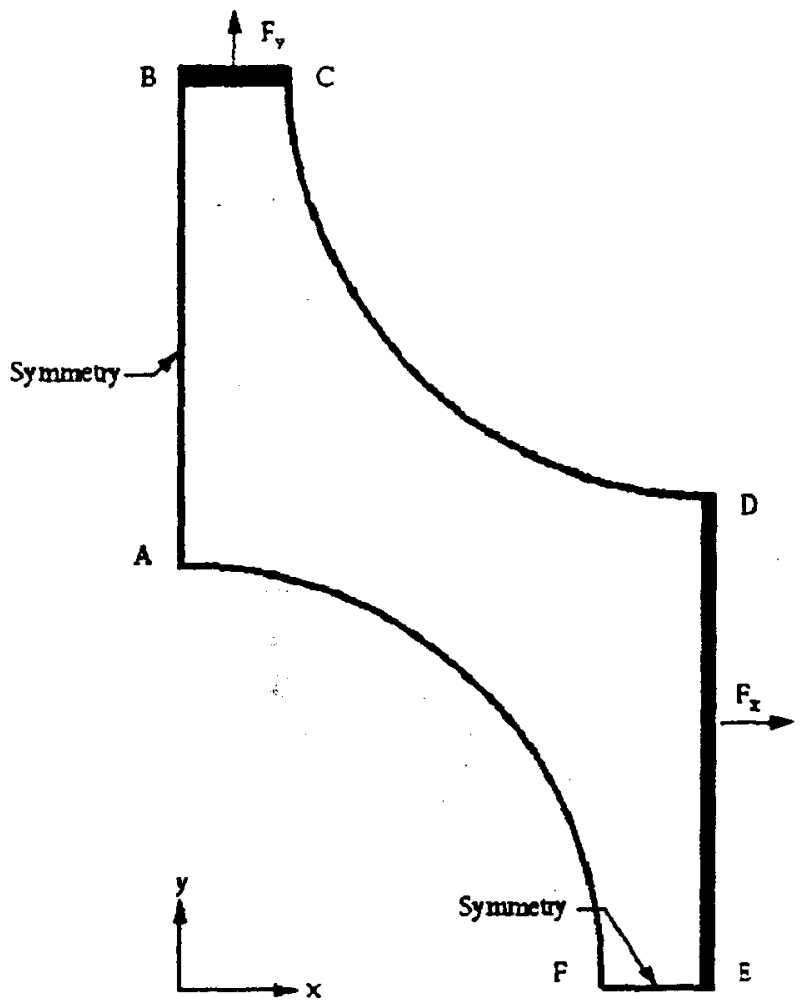

Figure 5. Boundary Conditions for $F_{x y}$ Case

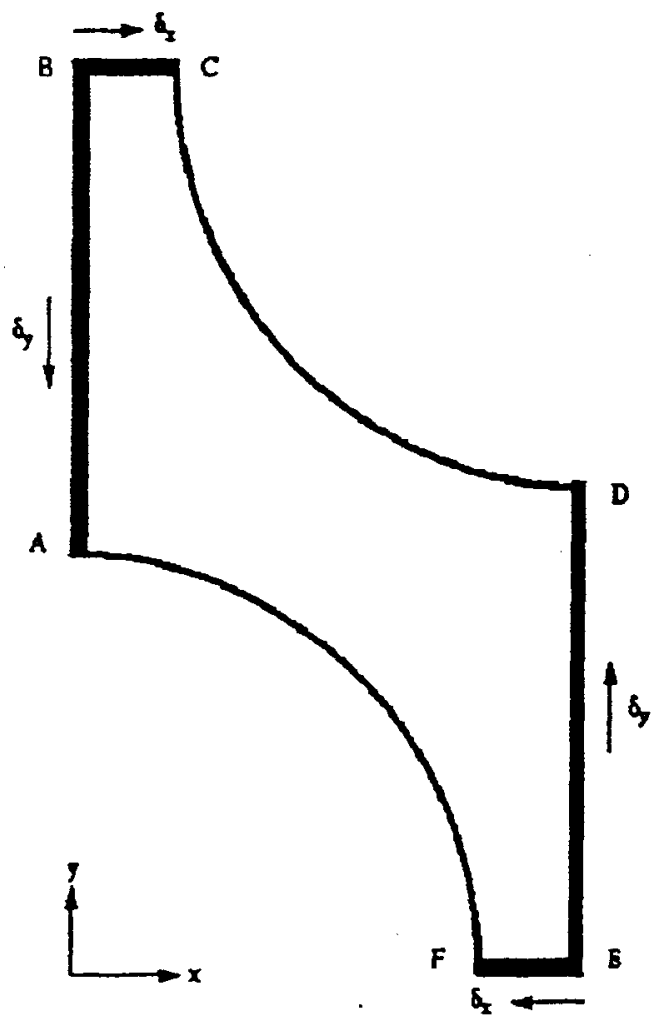

\section{MODEL VERIFICATION}

Each of the FEA models was checked by first obtaining elastic solutions and compairing the equivalent solid plate effective constants for the various ligament efficiencies against other published results. Table 1 compares $E^{*} / E$ and $u^{*}$ as a function of $h P$ to the values given in Slot[7]. Additionally, the peak elastic stress on the penetration surface is compared to Slot's [7] values to assure mesh adequacy. These values are also given in Table 1. Since the analysis results are all within $1 \%$ of the published values, it was judged that the mesh was adequate and the boundary conditions were applied property for these models. 


\section{RESULTS}

Figures $6,7,8,9,10$ and 11 show the collapse surfaces generated by the FEA results for the six ligament efficiencies used in the study. Tables 2 through 7 provide the data for the collapse surfaces. The MATHEMATICA [5] program is used to fit Equation (3) to the collapse surface data, Tables 2 through 7, by first calculating the $Q$ term, Equation (5), to match the $\tau_{x y}$ case given in Table 8 for each ligament efficiency. Coefficients $M, R$, and $T$ are then fit to the data points shown in the figures. The coefficients $M, R$, and $T$ are given in Table 9.

The comparisons in Figures 6-11 suggest that the fourth-order function is a reasonable fit to the collapse surface for $h / P>0.15$. For $h / \mathcal{P}<0.15$, it appears that the fourth-order function is not adequate to represent the surface.

The goal of this work is to utilize the general flow theory developed by Jones et. al. [4] and the coefficients developed here in a general EQS-EPP algorithm for commercial programs such as ABAQUS. This can be easily accomplished by a tablular look-up method with linear interpolation.

To demonstrate the accuracy of such a procedure, consider a ligament efficiency of 0.32 . Linear interpolation between the known values of 0.30 and 0.5 gives the coefficients of

$M=0.53890$

$Q=12.517$

$R=3.6261$

$T=8.5819$

Gordon et. al. [3] obtained the following coefficients by fitting the collapse surface resulting from a unit cell with a ligament efficiency of 0.32 :

$$
\begin{aligned}
& M=0.52971 \\
& Q=11.86453 \\
& R=3.96229 \\
& T=7.57493
\end{aligned}
$$

There is very little difference in these coefficients thus validating the proposed linear interpolating procedure. The actual FEA collapse surface was obtained by Gordon et. al. [3] and the data is compared to the approximate surface in Figure 12. Using the coefficients of Equation (7), Equation (3) is $11 \%$ conservative relative to the FEA data. The largest error occurs in quadrants 2 and 4.

\section{CONCLUSIONS}

Collapse surfaces are developed for thick perforated plates containing a triangular penetration pattem with ligament efficiencies of $0.05,0.10,0.15,0.2,0.3$, and 0.5 using elasticperfectly plastic FEA analysis. The FEA data was fit to a fourth-order collapse function and the resulting fitted curves compared to the original data. Based on this work, the following conclusions are drawn:

- The fourth-order yield function is a reasonable fit to the FEA data for $0.15<\mathrm{h} / \mathrm{P}<0.50$.

- The fourth-order yield function appears to be unable to reproduce the shape of the collapse surface for $h / P<0.15$. An alternate formulation is thought to be appropriate for this range.

- A table look-up method with linear interpolation is a reasonable way to obtain the coefficients for the fourth-order function for $0.15<h / P<0.50$. This method produce d a surface with an $11 \%$ maximum deviation from $F E A$ data for $h / P=0.32$. 


\section{ACKNOWLEDGEMENT}

The analysis presented here was performed under a U.S. Department of Energy contract with Bechtel Bettis, Inc. The authors are greatful to Ms. Virginia Ogurchak and Ms. Bernadette Holly for their help in preparing this document.

\section{REFERENCES}

[1] W. D. Reinhardt, "Yield Criteria for the Elastic Plastic Design of Tubesheets with Triangular Penetration Patterns", presented at the 1998 ASME PVP Conference, PVP Vol. 370, Finite Element Applications: Linear, Non-Linear, Optimization and Fatigue and Fracture, pgs. 113-120, 1998.

[2] Reinhardt, W., "A Fourth-Order Equivalent Solid Model for Tubesheet Plasticity," presented at the 1999 ASME PVP Conference, PVP-Vol. 385, Computer Technology - 1999 August 1999, pgs.151-158.

[3] J.L. Gordon, Jones, D.P., Banas D., and Hutula, D.N., “A Collapse Surface for a Perforated Plate with an Equilateral Triangular Array of penetrations," presented at the 1999 ASME PVP Conference, PVP-Vol. 385, Computer Technology - 1999 August 1999, pgs.125-134.

[4] D. P. Jones, J. L. Gordon, Hutula, D. N., Banas, D., Newman, J. B., "An Elastic-Plastic Flow Model for Finite Element Analysis of Perforated Materials," presented at the 1999 ASME PVP Conference, PVP-Vol. 385, Computer Technology - 1999 August 1999, pgs.175-184.

[5] MATHEMATICA 4.0 for Silicon Graphics, 1999, A System for Doing Mathematics by Computer, Wolfram Research, Inc. Champaign, IL, USA.
[6] ABAQUS: Theory Manual Version 5.8, Hibbitt, Karlsson \& Sorensen, Inc., Farmington Hills, MI, 1998.

[7] Slot, T., 1972, "Stress Analysis of Thick Perforated Plates," Ph.D. Thesis, Dept. of Mech. Engr., The University of Technology Delft, the Netherlands, Technomic Publishing Co., Inc. 
Table 1. Elastic check cases.

\begin{tabular}{|c|c|c|c|}
\hline h/P & $E * / E$ & $v^{*}$ & $\sigma_{30^{\circ}}\left(S_{1}\right.$ \\
\hline 0.05 FEA & 0.0172 & 0.8078 & 17.44 \\
\hline 0.05 Slot & 0.0172 & 0.8078 & 17.53 \\
\hline 0.10 FEA & 0.0521 & 0.6606 & 11.92 \\
\hline 0.10 Slot & 0.0520 & 0.6606 & 11.92 \\
\hline 0.15 FEA & 0.0994 & 0.5444 & 8.782 \\
\hline 0.15 Slot & 0.0994 & 0.5445 & 8.790 \\
\hline 0.20 FEA & 0.1553 & 0.4574 & 6.834 \\
\hline 0.20 Slot & 0.1553 & 0.4575 & 6.844 \\
\hline 0.30 FEA & 0.2805 & 0.3541 & 4.639 \\
\hline 0.30 Slot & 0.2806 & 0.3540 & 4.654 \\
\hline 0.50 FEA & 0.5447 & 0.2992 & 2.790 \\
\hline 0.50 Slot & 0.5446 & 0.2994 & 2.841 \\
\hline
\end{tabular}

Table 2. Collapse data for $h / P=0.05$.

\begin{tabular}{|c|c|c|}
\hline Case & $\sigma_{x} / S_{y}$ & $\sigma_{n} / s_{y}$ \\
\hline$T$ & 0.679053 & 1.176154 \\
\hline 2 & 0 & 0.681231 \\
\hline 3 & 0.626647 & 0 \\
\hline 4 & 0.251503 & -0.43562 \\
\hline 5 & 0.25963 & 0.899231 \\
\hline 6 & 0.157084 & 0.816154 \\
\hline 7 & 1.183568 & 1.024615 \\
\hline 8 & 0.720355 & 0.124769 \\
\hline 9 & 0.835826 & 0.289538 \\
\hline 10 & 0.972169 & 0.505077 \\
\hline 11 & 1.107624 & 0.767308 \\
\hline 12 & 1.162695 & 1.208462 \\
\hline 13 & 0.99704 & 1.208462 \\
\hline 14 & 0.872243 & 1.208462 \\
\hline 15 & 0.775426 & 1.208462 \\
\hline 16 & 1.197336 & 1.089231 \\
\hline 17 & 1.209327 & 1.151538 \\
\hline 18 & 1.21288 & 1.208462 \\
\hline
\end{tabular}

Full collapse surface obtained by symmetry.
Table 3. Collapse data for $h / P=0.10$.

\begin{tabular}{|lrr|}
\hline Case & \multicolumn{1}{c}{$\sigma_{x}{ }_{y} S_{y}$} & $\sigma_{y} / S_{y}$ \\
\hline 1 & 0 & 0.931754 \\
3 & 0.810955 & 0 \\
4 & 0.709031 & 1.228077 \\
5 & 0.345966 & -0.61077 \\
6 & 1.199112 & 1.038462 \\
7 & 0.340193 & 1.178846 \\
8 & 0.210733 & 1.095 \\
9 & 1.001037 & 0.346923 \\
10 & 1.142487 & 0.791538 \\
11 & 1.181792 & 1.228077 \\
12 & 0.886233 & 1.228077 \\
13 & 0.212754 & -0.73692 \\
14 & -0.39437 & 0.546538 \\
15 & 0.152976 & -0.795 \\
16 & 0.655515 & -0.22704 \\
17 & 0.540933 & -0.37481 \\
\hline
\end{tabular}

Full collapse surface obtained by symmetry.

Table 4. Collapse data for $h P=0.15$.

\begin{tabular}{|c|c|c|}
\hline Case & $\sigma_{\alpha}{ }_{\mu} S_{y}$ & $\sigma_{y} / \mu S_{y}$ \\
\hline 1 & 0 & 1.061538 \\
\hline 2 & 0.881273 & 0 \\
\hline 3 & 0.725833 & 1.257179 \\
\hline 4 & 0.397187 & -0.68795 \\
\hline 5 & 1.225907 & 1.061795 \\
\hline 6 & 0.362842 & 1.256923 \\
\hline 7 & 0.235233 & 1.222308 \\
\hline 8 & 1.032865 & 0.357692 \\
\hline 9 & 1.16758 & 0.808974 \\
\hline 10 & 1.209623 & 1.257179 \\
\hline 11 & 0.90718 & 1.257179 \\
\hline 12 & 0.244412 & -0.84692 \\
\hline 13 & 0.175574 & -0.91256 \\
\hline 14 & 0.731754 & -0.25351 \\
\hline 15 & 0.61288 & -0.42462 \\
\hline 16 & 0.521688 & -0.54205 \\
\hline 17 & 0.451666 & -0.6259 \\
\hline 18 & 1.252554 & 1.193333 \\
\hline
\end{tabular}

Full collapse surface obtained by symmetry. 
B-T-3300

Page 11

Table 5. Collapse data for $h P=0.20$.

\begin{tabular}{|lrr|}
\hline \multicolumn{1}{|c}{ Case } & \multicolumn{1}{c|}{$\sigma_{x d} / \mu \boldsymbol{S}_{\gamma}$} & \multicolumn{1}{c|}{$\sigma_{n} / \mu \boldsymbol{S}_{\mathrm{y}}$} \\
\hline 1 & 0 & 1.124808 \\
2 & 0 & -1.12481 \\
3 & 0.908105 & 0 \\
4 & 0.747558 & 1.294808 \\
5 & 0.422354 & -0.73154 \\
6 & 0.93453 & 1.295 \\
7 & 1.202665 & 1.249808 \\
8 & 1.25718 & 1.088654 \\
9 & 1.194116 & 0.827308 \\
10 & 1.125611 & 0.584808 \\
11 & 1.053886 & 0.365 \\
12 & 0.373834 & 1.295 \\
13 & 0.246373 & 1.28 \\
14 & 1.140711 & 1.284231 \\
15 & 1.068098 & 1.295 \\
16 & 0.996928 & 1.295 \\
17 & 0.830718 & 1.295 \\
18 & 0.598113 & 1.295 \\
19 & 0.498409 & 1.294808 \\
20 & 0.427239 & 1.294808 \\
\hline
\end{tabular}

Full collapse surface obtained by symmetry.

Figre 6. Collapse Surface for $h P=0.05$

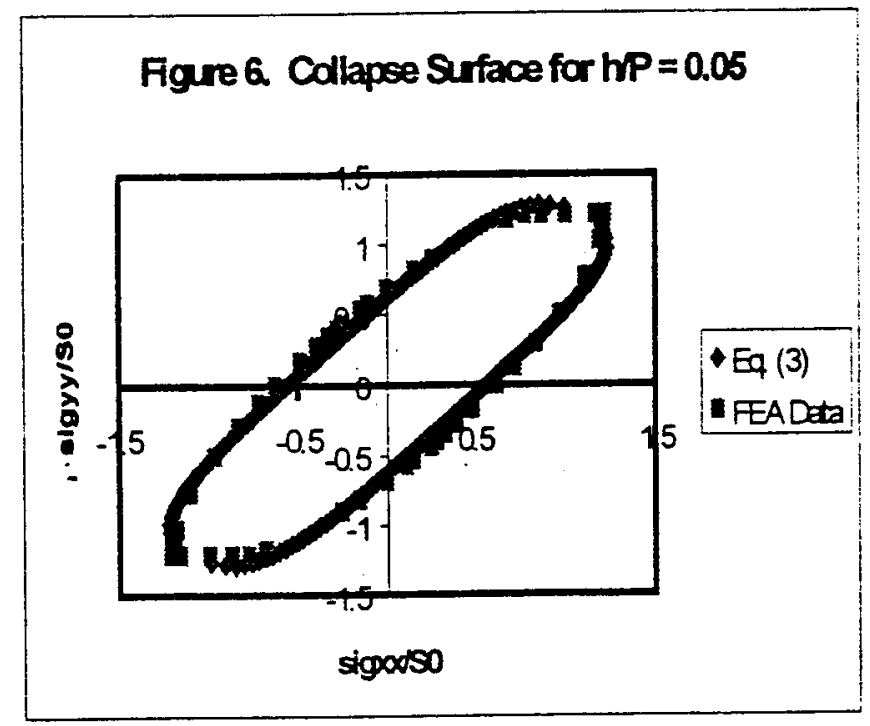

Table 6. Collapse data for $h P=0.30$.

\begin{tabular}{|lrr|}
\hline \multicolumn{1}{c}{ Case } & \multicolumn{1}{c|}{$\sigma_{x} d \mu \boldsymbol{S}_{Y}$} & \multicolumn{1}{c|}{$\sigma_{n} / \mu \boldsymbol{S}_{Y}$} \\
\hline 1 & 0 & 1.188077 \\
2 & 0.940267 & 0 \\
3 & 0.786529 & 1.362308 \\
4 & 0.447817 & -0.77564 \\
5 & 1.259956 & 1.091154 \\
6 & 0 & -1.18808 \\
7 & 0.394967 & 1.368333 \\
8 & 0.257217 & 1.336538 \\
9 & 0.629534 & -0.54526 \\
10 & 1.094301 & 0.379103 \\
11 & 1.254627 & 0.869231 \\
12 & 1.166396 & 1.212179 \\
13 & 0.955589 & 1.324103 \\
14 & 0.27624 & -0.95705 \\
15 & 0.19815 & -1.02949 \\
16 & 0.800296 & -0.27718 \\
17 & 0.680459 & -0.47141 \\
18 & 0.584234 & -0.60718 \\
19 & 0.508142 & -0.7041 \\
\hline
\end{tabular}

Full collapse surface obtained by symmetry.

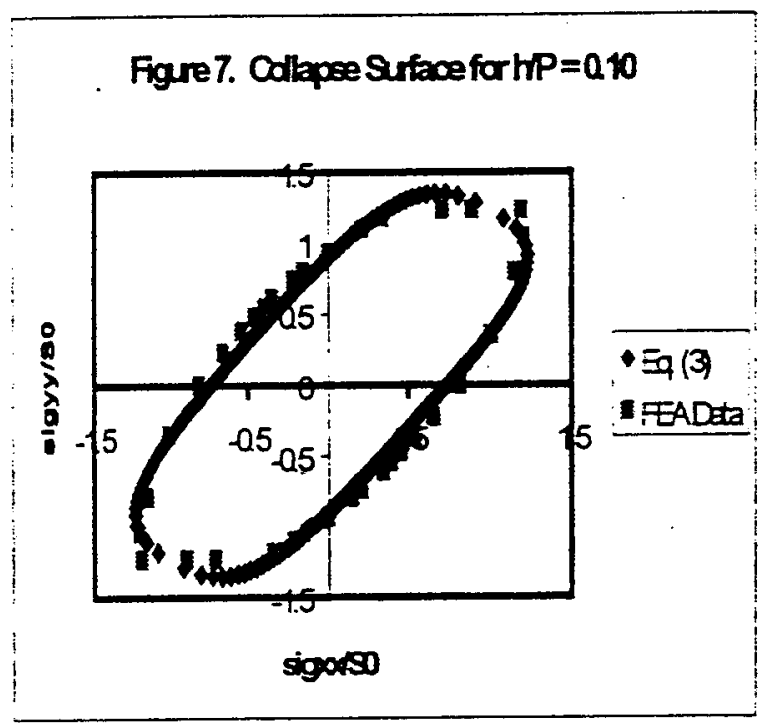


Table 7. Collapse data for $h P=0.50$.

\begin{tabular}{|c|c|c|}
\hline Case & $\sigma_{\alpha} / \mu \mathbf{S}_{y}$ & $\sigma_{0} / \mu S_{y}$ \\
\hline 1 & 0.787728 & 1.364385 \\
\hline 2 & 1.313783 & 0.910231 \\
\hline 3 & 0.468808 & -0.812 \\
\hline 4 & 0 & 1.243615 \\
\hline 5 & 1.003479 & 0 \\
\hline 6 & 0.260607 & 1.354154 \\
\hline 7 & 0.398238 & 1.379538 \\
\hline 8 & 0.65929 & -0.57092 \\
\hline 9 & 1.098253 & 0.190231 \\
\hline 10 & 1.203331 & 0.416846 \\
\hline 11 & 1.314049 & 0.682769 \\
\hline 12 & 1.245122 & 1.078308 \\
\hline 13 & 1.147772 & 1.192769 \\
\hline 14 & 1.045004 & 1.267 \\
\hline 15 & 0.948942 & 1.314923 \\
\hline 16 & 0.863005 & 1.345308 \\
\hline 17 & 0.289297 & -1.00215 \\
\hline 18 & 0.20758 & -1.07854 \\
\hline 19 & 0.841999 & -0.29169 \\
\hline 20 & 0.713028 & -0.494 \\
\hline 21 & 0.611769 & -0.63577 \\
\hline 22 & 0.532184 & -0.73746 \\
\hline
\end{tabular}

Full collapse surface obtained by symmetry.

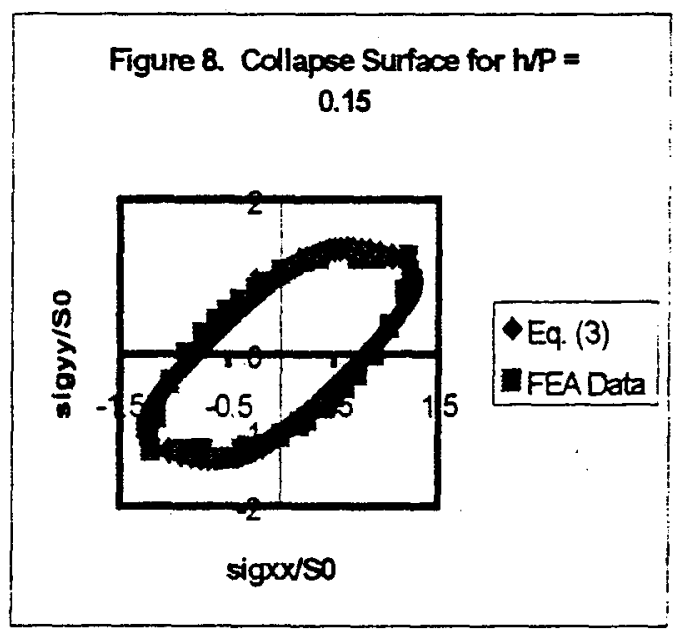

Table 8. Collapse data for shear case.

\begin{tabular}{|cc|}
\hline $\boldsymbol{h} / \mathrm{P}$ & Coefiicient Q \\
\hline 0.05 & 125.375 \\
0.10 & 34.862 \\
0.15 & 20.096 \\
0.20 & 15.564 \\
0.30 & 12.777 \\
0.50 & 10.185 \\
\hline
\end{tabular}

Fogere collapse Surtice for $b / P=0.20$

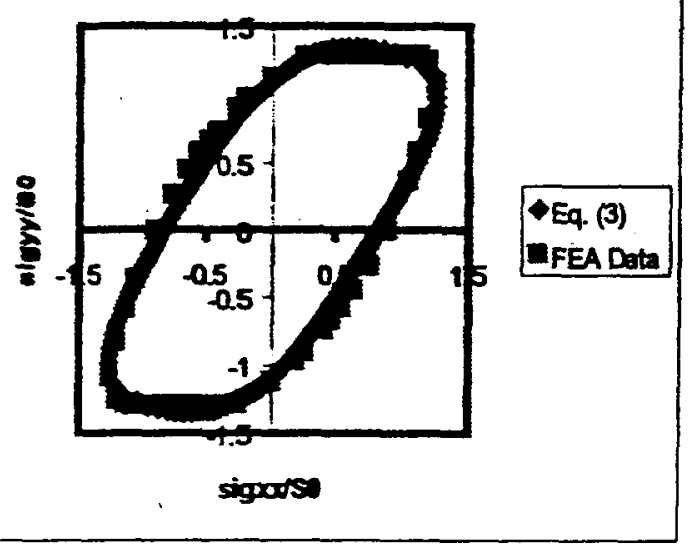

Figure 10. Collapse Surface for h/P = 0.30

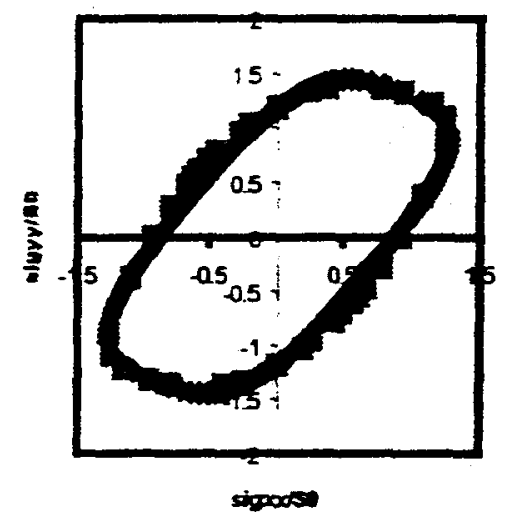

AEq. (3) IFEA Data 


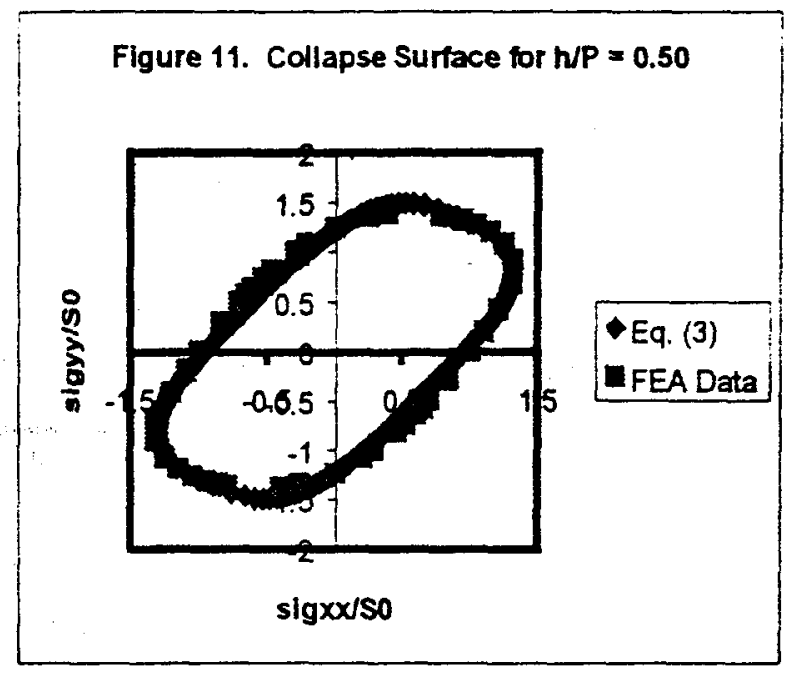

Figure 12 Collapse Surface for $h / P=0.32$

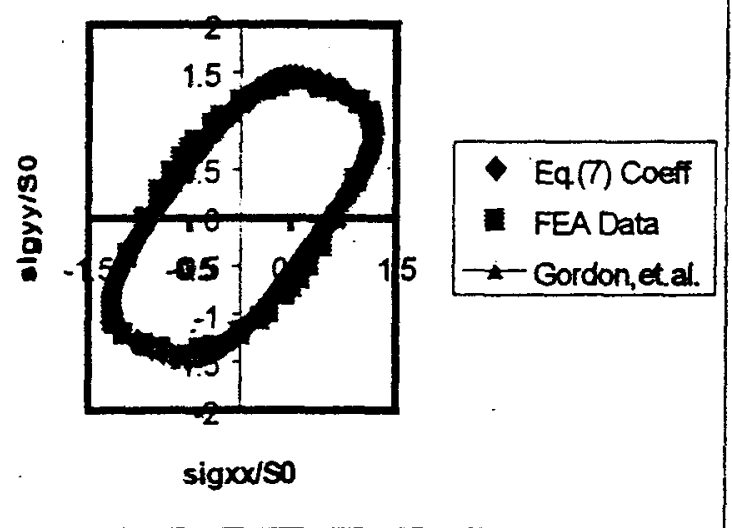

Table 9. All coefficients as function of $h / P$.

\begin{tabular}{|lrlll|}
\hline $\boldsymbol{h} / \mathrm{P}$ & $\mathrm{M}$ & $\mathrm{Q}$ & $\mathrm{R}$ & $\mathrm{T}$ \\
\hline $\mathbf{0 . 0 5}$ & 0.57056 & 125.375 & 5.2295 & 25.843 \\
$\mathbf{0 . 1 0}$ & 0.61810 & 34.862 & 3.9838 & 14.710 \\
$\mathbf{0 . 1 5}$ & 0.51872 & 20.096 & 5.2035 & 11.981 \\
$\mathbf{0 . 2 0}$ & 0.50052 & 15.564 & 6.3047 & 11.344 \\
$\mathbf{0 . 3 0}$ & 0.53590 & 12.777 & 3.7841 & 8.8850 \\
$\mathbf{0 . 5 0}$ & 0.56594 & 10.185 & 2.2037 & 5.8536 \\
\hline
\end{tabular}

